\title{
Algumas considerações nietzschianas sobre corpo e saúde
}

Carlos Augusto Peixoto Junior ${ }^{1}$

PEIXOTO JUNIOR, C.A. Some Nietzschean considerations about body and health.

Interface - Comunic., Saude, Educ., v.14, n.35, p.727-38, out./dez. 2010.

Trying to emphasize the importance of some Nietzschean considerations for the understanding one may have about body and health, the present work starts from the critique formulated by Nietzsche to metaphysics and Platonism to discuss his point of view about the relations between body and conscience. Based on this and having as main reference the concept of will of power, the current work tries to show how the body could be conceived as a metaphor to which Nietzsche resorts in his critical interpretation of subjectivity and culture.

Keywords: Body. Health. Conscience. Interpretation.
No intuito de ressaltar a importância de algumas considerações nietzschianas para o entendimento que se pode ter do corpo e da saúde, o presente trabalho parte da crítica formulada por Nietzsche à metafísica e ao platonismo para discutir o seu ponto de vista a propósito das relações entre corpo e consciência. A partir daí, tendo como referência principal o conceito de vontade de potência, procura-se mostrar como o corpo poderia ser concebido como uma metáfora à qual Nietzsche recorre em sua interpretação crítica da subjetividade e da cultura.

Palavras-chave: Corpo. Saúde.

Consciência. Interpretação.

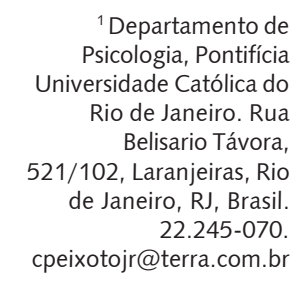

${ }^{1}$ Departamento de Psicologia, Pontifícia Rio de Janeiro. Rua
Rusidade Católica do Belisario Távora, 1/102, Laranjeiras, Rio
de Janeiro, RJ, Brasil. cpeixotojr@terra.com.br 


\section{Introdução}

O corpo e a saúde sempre foram temas instigantes para todos aqueles que se interessaram em compreender o homem e sua posição no mundo. Desde os anos 1960, pelo menos, tornou-se comum falar da importância e do valor que adquiriram, na nossa sociedade, o culto ao corpo, associado a uma noção de saúde prescritiva bastante questionável. E isso a tal ponto que alguns chegam mesmo a dizer que estaríamos vivendo em uma cultura somática. No entanto, algumas questões fundamentais se colocam caso queiramos compreender como teríamos chegado a esse estado de coisas: será que são esses os corpos e essa saúde que realmente importam se queremos construir um mundo mais afirmativo no que se refere à diferença e à singularidade? E, afinal, quais seriam os modelos de corpo e saúde que teriam se tornado dominantes até os dias atuais? Do nosso ponto de vista, trata-se, no caso, de duas concepções fundadas prioritariamente em uma perspectiva normativa sobre os corpos e as saúdes possíveis, a qual se constituiu na esteira de uma determinada tradição que precisaria ser questionada de forma bastante incisiva. É nesse sentido que a obra de Nietzsche pode nos servir como um instrumento fundamental de luta contra esse modelo homogeneizante e serializado, posto que ele certamente foi o pensador que mais se dedicou a combater os valores tradicionais que se encontram na base da atual valoração de um determinado tipo de corpo e do conceito vigente de saúde.

No decorrer do presente trabalho, portanto, pretendemos buscar, na sua obra, alguns indícios que nos permitem formular uma visão crítica dessas noções de corpo e saúde, procurando mostrar como o pensamento nietzschiano pode contribuir para o estabelecimento de uma nova perspectiva, que não apenas coloca em questão o ponto de vista da tradição, mas que também nos abre novas alternativas para pensar o corpo e a saúde no que esses fenômenos contribuem para uma outra visão, mais afirmativa, sobre o homem e o mundo. No intuito de alcançarmos esse objetivo, partimos da crítica formulada por Nietzsche à metafísica e ao platonismo para, em seguida, discutirmos o seu entendimento a propósito das relações entre corpo e consciência. A partir daí, tendo como referência o conceito de vontade de potência, procuramos entender como o corpo poderia ser concebido como uma metáfora à qual Nietzsche recorre em sua interpretação crítica da subjetividade e da cultura.

Para Nietzsche, quando se considera a história da filosofia, até agora, de um ponto de vista suficientemente crítico, pode-se constatar que "o pior, o mais inveterado, o mais perigoso de todos os erros foi um erro de dogmáticos: a invenção platônica do espírito puro e do Bem em si" (Nietzsche, 1971, p.18). Se é desse pesadelo dogmático que o pensamento crítico pode nos despertar, nossa tarefa, como pensadores contemporâneos, consiste precisamente em permanecermos despertos e, justamente por isso, colocarmos a verdade novamente sobre os próprios pés, pois o sortilégio de Platão consistiu em colocá-la de cabeça para baixo.

Embalada pela crença na invenção platônica do espírito puro e do Bem em si, a herança filosófica de Platão reputou o subjetivo-perspectivístico como o contrário da verdade, isto é, como erro, engano, ilusão. Segundo Giacoia Junior (2003, p.24), "Se essa invenção em si é uma ousada inversão de valores, e uma vez que conseguimos despertar do pesadelo platônico, então nossa tarefa mais autêntica e radical consiste em subverter a inversão platônica". E esse é também um dos principais sentidos do programa filosófico nietzschiano da transvaloração de todos os valores.

Com o platonismo temos uma concepção de filosofia como exercício ascético, vale dizer, em termos extremos, como preparação para a morte, pela qual a alma se redimiria da prisão do corpo e retornaria à divindade de sua origem. Nietzsche identifica esse traço ascético com uma espécie de pecado original da metafísica, a partir do qual a filosofia se institui como negação e desvalorização do sensível, do corpo, da materialidade, do movimento, do transitório, do devir e da multiplicidade. No projeto metafísico, o que em nós é corpo, é precisamente aquilo que deve ser afastado para que possamos ter acesso ao reino puro das essências.

Se a tradição platônico-cristã se erigiu sobre a base da crença no primado da alma - e se essa tradição ruiu -, então, por que não tomar como fio condutor o complexo campo de fenômenos constituído pelo corpo? "O corpo pode servir de paradigma para a constituição de uma hipótese sobre a subjetividade, muito mais rica e plausível do que aquela formulada pela metafísica e pelo platonismo" (Giacoia Junior, 2001, p.59). 


\section{A consciência e o corpo}

De acordo com Deleuze (1976), Nietzsche sabe que chegou a hora de chamar a consciência à modéstia necessária, e tomá-la pelo que ela é: um sintoma de uma transformação mais profunda e da atividade de forças de uma ordem que não é espiritual. Em toda a evolução do espírito, talvez não se trate de outra coisa que não corpo: é a história se tornando sensível a que um corpo superior esteja sendo formado. Centenas de milhares de experiências são feitas para modificar a alimentação, a forma de morar e de viver no corpo: nele, dizia o filósofo alemão, a consciência e as apreciações de valores, todos os tipos de prazer e desprazer são indícios dessas modificações e dessas experiências.

Para Nietzsche, o que define um corpo são as relações entre forças dominantes e forças dominadas. Toda relação de forças constitui um corpo: químico, biológico, social, político. Duas forças quaisquer, sendo desiguais, constituem um corpo desde que entrem em relação; por isso, no sentido nietzschiano, o corpo é sempre fruto do acaso e surge como aquilo que é mais surpreendente, muito mais surpreendente, na verdade, do que o espírito ou a consciência. Em seus fragmentos póstumos (Nietzsche, 1979), o autor afirma que o corpo humano é um pensamento mais surpreendente do que a alma, e que não nos cansamos de nos maravilhar com a ideia de que o corpo humano tornou-se possível.

Do ponto de vista deleuziano,

o corpo é um fenômeno múltiplo e composto por uma pluralidade de forças irredutíveis; sua unidade é a de um fenômeno múltiplo, unidade de dominação, em termos nietzschianos. Em um corpo, são consideradas ativas as forças dominantes ou superiores, e reativas aquelas inferiores ou dominadas. (Deleuze, 1976, p.33)

Segundo Pierre Klossowsky, o corpo quer se fazer compreender por meio de uma linguagem de signos, falaciosamente decifrados pela consciência: esta constitui esse código de signos que inverte, falsifica e filtra aquilo que se expressa através do corpo. Nestes termos, a própria consciência é apenas o código cifrado das mensagens transmitidas pelos impulsos: a decifração é, em si, a inversão da mensagem que o indivíduo se atribui.

Neste sentido, Nietzsche não defende uma "higiene" do corpo estabelecida pela razão, defendendo os estados corporais como dados autênticos que a consciência não pode deixar de escamotear por ser um deles. Para Klossowsky (2000, p.46-7), "tal concepção vai muito além de um ponto de vista meramente fisiológico a propósito da vida. Resultado do acaso, o corpo é apenas o lugar do encontro de um conjunto de impulsos individualizados para esse intervalo formado pela vida humana, os quais aspiram a perder a individualidade".

Remetendo o consciente, o espírito, como signo, à profundidade do fundamento, Nietzsche quer dizer, mais uma vez, que tudo o que está em evidência é apenas signo: a profundidade do mundo é que tudo é signo - o corpo sendo a instância principal onde o caos do mundo é inicialmente reduzido por cada pulsão para ser novamente pluralizado. O corpo, como unidade-pluralidade, é o lugar da interpretação que constitui o caos do mundo em unidades plurais, em signos.

A consciência confunde a unificação-simplificação do signo consciente com a unificação do caos pelo corpo, promovendo um curto-circuito no corpo como jogo de unidade-pluralização das pulsões. Neste sentido, superestimar o consciente seria considerar o signo como uma coisa em si. Considerando essa questão, Nietzsche recoloca a consciência diante da pluralidade invisível do corpo à qual ela está submetida: "a consciência é um órgão como o estômago" (Nietzsche, 1982a, p.251). "O intelecto é apenas o instrumento cego de uma outra pulsão" (Nietzsche, 1980, p.89).

Como dizia Zaratustra, criticando aqueles que desprezam o corpo, "essa pequena razão que tu chamas de 'espírito', meu irmão, é apenas um instrumento de teu corpo, um instrumento bem pequenino, um joguete da tua grande razão" (Nietzsche, 1969, p.51). A consciência, como joguete, é um objeto polissêmico. Inversamente, desprezar o corpo é rebaixar o mundo, fazer dele uma série de objetos, ao invés de um campo de interpretações. Assim, a consciência é apenas o lugar no qual o plural se diz como particularidade, uma espécie de reflexo em espelho ou linguagem cifrada que designa algo de fundamentalmente outro. Ao invés de entendermos o estado consciente como um instrumento, um 
mero detalhe da vida como um todo, o tomamos como critério ou como estado de valor supremo diante da vida: resumindo, trata-se de uma perspectiva errônea que toma a parte pelo todo. Em última instância, a consciência não passa de abreviação de uma pluralidade: a do corpo como texto.

Nestas condições, perguntar-se sobre o que é o corpo é também perguntar-se sobre o que é a interpretação. E a descrição do corpo interpretante se apoia sobre metáforas que se interpenetram: metáfora gastroenterológica, metáfora política, metáfora filológica. Em um de seus fragmentos póstumos, Nietzsche (1979) nos mostra que, visivelmente, o intelecto não passa de um instrumento nas mãos dos afetos, os quais constituem uma pluralidade. Guiados pelo fio condutor do corpo, aprendemos que nossa vida só é possível graças ao jogo de inúmeras inteligências de valor bastante desigual, isto é, graças a uma perpétua troca de obediência e comando sob as formas mais diversas. O fenômeno do 'corpo', do ponto de vista intelectual, seria "tão superior à nossa consciência, ao nosso espírito, à nossas maneiras conscientes de pensar, de sentir e de querer, quanto a álgebra é superior à tábua de multiplicação" (Nietzsche, 1979, p.198). Para dar conta dessa relação não aritmética, Nietzsche se serve dos esquemas metafóricos, constituindo uma rede de metáforas. Tais metáforas são úteis para pensar a unidade do plural e a pluralidade singular do corpo interpretante.

\section{O corpo e a interpretação}

De acordo com Éric Blondel (1986), Nietzsche teria retirado todos os recursos da linguagem para dizer o que ela recobre: o corpo, a realidade. Segundo o comentador francês, "para dizer algo sobre o corpo, Nietzsche vai relativizar a linguagem e a filologia. Mas, ao invés de deslocar o acento para a fisiologia, como se poderia esperar, ele procura representar o mundo das pulsões e instintos criando uma nova linguagem" (Blondel, 1986, p.279). A genealogia, buscando pensar filosoficamente a cultura, relaciona os ideais com o corpo como sua origem escondida. Nietzsche se propõe então a enunciar o que se deve entender por corpo e esclarecer a noção de origem.

Recorrendo ao corpo, o filósofo procura recusar tanto o idealismo espiritualista quanto o mecanicismo ou biologismo. No primeiro, o corpo é subutilizado, e, no segundo, ele é conceituado de forma puramente objetivista. A isso o autor opõe, por um lado, a primazia do corpo e, por outro, uma concepção não-empirista. Não é possível remeter os ideais ao corpo simplesmente reabsorvendo os primeiros no segundo, nem tampouco recair no dualismo. O monismo nietzschiano repousa, portanto, sobre a união-separação do ideal e do corpo: tal união-separação será explicitada segundo o eixo da interpretação. As imagens utilizadas por Nietzsche no âmbito da fisiologia não são exatamente imagens sensíveis: elas levam, ao contrário, à noção filológica de interpretação. Mas será que nessa contestação do dualismo mente-corpo trata-se apenas de reduzir o homem e a cultura ao corpo, o espírito e a consciência ao organismo?

O parágrafo 14 de $O$ Anticristo indica uma possível solução, e se inicia por uma recusa do espírito: "nos tornamos em todos os pontos mais modestos. Não buscamos mais a origem do homem no 'espírito', na 'natureza divina', nós os substituímos pelo nível dos animais" (Nietzsche, 1974a, p.24-5). Como animal, o homem é corpo, e ainda que não haja simetria fisiológica, o homem não é o animal mais perfeito. Nestes termos, Nietzsche opõe sua concepção tanto à visão antropológica da Gênese quanto aos subentendidos ideológicos finalistas da teoria evolucionista de Darwin. Para ele, a animalidade do homem, como segurança proporcionada pelo instinto, é diminuída pela precariedade do pensamento consciente. Essa dimensão precária não serve apenas para contestar uma visão orgulhosa do homem ou, ainda, um antropocentrismo: com relação ao monismo da redução à animalidade, ela introduz no homem uma distância da qual testemunham esses fenômenos que costumamos chamar - erradamente segundo Nietzsche - de "espírito", "consciência", "vontade livre" e que são, simplesmente, "sintomas de uma certa imperfeição do organismo" (Nietzsche, 1974a, p.25). Além disso, o autor descreve esses fenômenos como uma multiplicidade: espírito e corpo são apenas um, mas essa unidade é plural. " $[A$ "vontade" é] uma resultante, uma espécie de reação individual, que dá necessariamente lugar a uma multidão de solicitações em parte contraditórias, em parte concordantes" (Nietzsche, 1974a, p.25).

Mas, então, se a consciência ou o espírito são modos do corpo, em que sentido se poderia dizer que o homem é "inteiramente corpo e nada além disso" (Nietzsche, 1969, p.51)? Com a noção de 
interpretação parece que se reintroduz sub-repticiamente a consciência no corpo. Para que serve a referência ao corpo, se assim ele é quase espiritualizado? Afinal, o que é o corpo como interpretação fundamental? De acordo com Blondel (1986, p.282-3),

o corpo são os instintos ou pulsões que, interpretando a realidade, a constituem. O curtocircuito real-espírito é substituído pelo desvio através do corpo que se interpõe entre o mundo e o espírito consciente. A partir daí surgem dois corolários: a constituição categorial é substituída pela interpretação corporal-pulsional; e o espírito-intelecto consciente se torna instrumento de um corpo interpretante inconsciente.

Portanto, não parece haver apenas uma simples reversão do dualismo anterior. O que há é uma interposição ou desvio, em conjunto com uma mudança de ordem.

O mundo como natureza bruta é caos; "o belo caos da existência" (Nietzsche, 1982b, p.189). Antes do corpo, não há ordem, relação ou texto; o mundo é o auge da multiplicidade. Ele só é texto para ou pelas pulsões que reduzem essa multiplicidade absoluta. Mas essa redução não é como aquela promovida pelo intelecto, a qual introduz uma unidade: se o corpo interpreta, ele o faz em termos de afetos, e, se os afetos interpretam, eles só instituem uma certa simplicidade para pluralizá-la. Os afetos constituem pontos de vista instáveis de um jogo no qual eles só existem no plural. O desvio nietzschiano pelo corpo é um desvio pelo plural das pulsões. Dado que os afetos interpretam, poderíamos dizer que não existem propriamente fatos, mas apenas interpretações. Nietzsche opõe o intelecto às pulsões como o simples à pluralidade.

Nestas condições, o corpo parece ser um elo intermediário entre o plural absoluto do caos do mundo e a simplificação absoluta do intelecto. Se a cultura e a humanidade começam com ele como interpretação, é precisamente no que ele é um lugar de articulação, e não propriamente fundamento, no que ele é um modelo dessa unidade-pluralidade ou um esquema da vontade de potência. Se o corpo é primeiro, ele o é como modelo de algo que é misto. Se a multiplicidade é primeira, o corpo, como jogo de afetos, será primeiro (como multiplicidade), em relação ao intelecto concebido como unificador-simplificador, enquanto será segundo em relação ao caos do mundo. Portanto, poderíamos dizer que Nietzsche não pretende reduzir o intelecto ao corpo, mas, apresentando o corpo como "pluralidade de intelectos", evidenciar o caráter radical dessa pluralidade.

A realidade do corpo é mais movimento e relação de forças do que substância ou coisa: isso é o que indicará a ideia da vontade de potência como determinação ontológica. A distância entre corpopensamento e pensamento consciente é mais uma distância entre múltiplo e simples do que entre consciente e inconsciente. Na verdade, o corpo é para Nietzsche "um mundo subterrâneo de órgãos ao nosso serviço" (Nietzsche, 2000, p.120).

Este mundo subterrâneo das pulsões inconscientes é menos uma causa ou uma natureza do que um invisível, reconhecido enquanto tal porque indecifrável por um pensamento da interpretação muito menos preocupado com o fundamento verdadeiro do que com a leitura, buscando um equilíbrio entre o fixo e o instável. Segundo Blondel, Nietzsche não tem apenas a intenção de

retomar a imagem da caverna platônica para mostrar que a relação ontológica de eminência, assim como a relação epistemológica de causalidade devem ser invertidas. O corpo subterrâneo não vem substituir o sol como causa e realidade verdadeira das aparências (sombras), como se, para Nietzsche, a sombra devesse ser, ao contrário de Platão, a razão última da luz enganadora (do consciente). (Blondel, 1986, p.286)

Com frequência, ele define essa obscuridade do corpo muito mais como um enigma filológico do plural do que como fundamento escondido, como oposição do visível (legível) simples à obscuridade do múltiplo. Na verdade, o filósofo chega mesmo a condenar explicitamente a ideia de que os afetos possam ser tomados como um fundamento ou causa. Em Aurora ele considera que "por mais longe que alguém possa levar o conhecimento de si, nada, no entanto, pode ser mais incompleto do que a imagem do conjunto de pulsões que constituem o seu ser" (Nietzsche, 1980, p.99). 
Se o conhecimento pretendido pelo espírito é impossível, resta-Ihe esquematizar, impondo ao caos alguma regularidade e algumas formas para satisfazer às nossas necessidades práticas. É por isso que, como vimos antes, do ponto de vista nietzschiano, o intelecto não seria senão um instrumento nas mãos dos afetos; e esses são uma pluralidade por trás da qual não há qualquer necessidade de postular uma unidade (Nietzsche, 1979). O intelecto deve se contentar em simplificar e igualar.

Processo multiforme, o corpo é, portanto, obscuro para o espírito consciente, o qual não domina sua contínua pluralidade. Essa é a razão pela qual Nietzsche compara o conjunto do corpo não consciente aos processos interiores do trato digestivo. Se ele é obscuro, não o é como um embasamento oculto à luz e à visão, mas no sentido de que sua pluralidade é inapreensível.

\section{A metáfora "gastroenterologia" do filósofo médico}

O pensamento de Nietzsche parece proceder por transferências. O movimento de algumas de suas metáforas ilustra por sua forma aquilo que seu conteúdo imaginário se propõe a explicitar, qual seja, a relação unidade-pluralidade. Algumas metáforas a propósito do corpo tendem a desembocar sobre um corpo como metáfora, unidade-pluralidade interpretativa, de modo que o corpo, utilizado metaforicamente para pensar a interpretação, parece que acaba por ser, ele próprio, interpretado como interpretação.

A metáfora gástrica, por exemplo, repousa sobre a ideia de assimilação, de dependência funcional. O estômago reduz o múltiplo ao singular assimilando-o. Mas essa assimilação supõe uma relação de forças que se opõem, resistem ou cedem, numa luta que desemboca sobre um estado de potência de vontades. Nestas condições, a metáfora gástrica poderia ser transportada para o âmbito de uma metáfora política: o corpo seria uma coletividade mais ou menos regrada, na qual uma determinada instância reina ou toma o poder, e, portanto, exclui, descarta ou escolhe, simplifica, iguala ou traduz, isto é, interpreta.

Em termos mais precisos, a filosofia nietzschiana não parece se propor a descrever fisiologicamente o corpo: o espírito é reduzido a um aspecto indevidamente privilegiado do organismo, enquanto que, inversamente, o organismo se vê atribuir um funcionamento espiritual que se estende à totalidade. Há, então, um espírito no sentido amplo, qual seja, o corpo. Para descrever esse corpo-espírito, o autor recorre a imagens da fisiologia gastroenterológica, sem valor fisiológico descritivo, mas que, por uma espécie de circuito fechado, serve de metáfora à interpretação. Se, ontologicamente, Nietzsche mantém o corpo como realidade primeira, por outro lado, do ponto de vista epistemológico, dada a sua recusa do "em si", o corpo parece funcionar antes de tudo como uma metáfora da interpretação, ou seja, um modo humano de interpretar. Neste contexto, segundo Blondel (1986, p.297-8), "seus textos aparentemente biologizantes, longe de reduzirem o ideal ao corpo são apenas tentativas de remeter a cultura (concebida como um corpo) à interpretação fundamental, o corpo fisiológico sendo um caso particular da interpretação dentre outros".

Considerando-se esta hipótese do comentador, a cultura, entendida como um corpo, e o corpo como sistema interpretativo seriam fenômenos da interpretação, ou do ser como interpretação, isto é, modos do interpretar. Do ponto de vista nietzschiano, a interpretação é um princípio quase-ontológico, do qual a vida, o corpo, a nutrição, a reprodução são "fenômenos derivados", casos particulares ou simples consequências da apropriação insaciável da vontade de potência (Nietzsche, 1976). Em última instância, a vontade de potência poderia ser tomada como uma interpretação à qual tudo é remetido.

No âmbito da metáfora gastroenterológica, o sistema digestivo, como metáfora da interpretação, procede, antes de tudo, assimilando: ele absorve aquilo que é estranho e se esforça para reduzi-lo à sua singularidade, à sua identidade múltipla, diversa e plural. No caso da nutrição saudável, trata-se de vencer um ser que resiste, e de se apropriar dele incorporando-o. Trabalho secreto, subterrâneo, obscuro e também repugnante. Entretanto, considera Nietzsche, ver as entranhas seria ver uma realidade verdadeira, realidade interior ao mesmo tempo ameaçadora e repugnante, misto de pudor $\mathrm{e}$ horror: como se a pluralidade caótica real inspirasse medo, tanto à consciência quanto à moral. É para opor uma verdade abominável ao charme superficial do ideal que Nietzsche, como filósofo médico, fala das entranhas. Elas constituem a realidade de um corpo que incorpora e assimila a pluralidade e têm 
como objetivo reduzir o excesso. O estômago deve, como a cultura e a interpretação, recusar coisas, dado o risco de disfunções. Como fica claro a partir de uma passagem de $A$ genealogia da moral (Nietzsche, 2000), a capacidade de absorção pode ser um critério de força: o homem forte, possuidor de uma boa saúde instintiva, digere seus atos exatamente como digere suas refeições, mesmo quando se trata de alimentos mais pesados.

Os problemas de absorção-assimilação podem assumir diversas formas, as quais o autor evoca com riqueza de detalhes em Para além de bem e mal: o espírito quer "remeter a multiplicidade à simplicidade", a partir de "uma tendência pronunciada a assimilar o novo ao antigo, a simplificar o complexo, a ignorar ou descartar o que é absolutamente contraditório"; ele "procura incorporar em si novas experiências", segundo "o grau de sua força de assimilação, de sua 'capacidade digestiva'" (Nietzsche, 1971, p.148-9).

Aplicando esse esquema à cultura e à interpretação, Nietzsche atribui a ele a finalidade de pôr fim a alguma coisa: absorver para aumentar a si próprio sem nada perder, mas sem se perder. $O$ autor denuncia o excesso "alimentar" e a "voracidade", aos quais ele opõe a escolha e a lentidão das operações fisiológicas, as quais, no campo isomorfo da filologia da interpretação, dizem respeito ao discernimento, à sutileza e ao ritmo lento. Nota-se, portanto, que a finalidade não é o dispêndio, mas uma certa forma de economia. Neste sentido, estar doente não é somente digerir mal, mas engolir tudo e eliminar mal: a cultura mórbida, dispéptica, é aquela que interpreta mal, assim como uma interpretação fraca engole e deixa passar tudo de um texto sem ruminá-lo.

Se os problemas digestivos podem provir dos excessos, eles muitas vezes se devem à "preguiça das entranhas" (Nietzsche, 1974b, p.115), resultado de uma má dietética. O conselho da ruminação destina-se a remediar essa falha. Mas a melhor maneira de prevenir esses aborrecimentos é preparar o corpo para movimentos que encorajem a atividade intestinal, esse fora do espírito-estômago. Donde a importância do tema da caminhada: ela ajuda a digerir e simboliza a exterioridade e a oposição a uma cultura livresca. Nesses termos, "adotar livremente um movimento"; "conhecer o tamanho do seu estômago"; considerar que "uma refeição copiosa é mais fácil de digerir do que uma refeição leve demais": eis alguns preceitos do que Nietzsche chama de sua moral.

\section{A saúde e a grande saúde}

Considerando-se os aspectos discutidos até aqui - e indo um pouco além da metáfora gastroenterológica, assim como das outras dimensões metafóricas da corporeidade mencionadas acima -, também se torna possível revelar, por trás de uma dada cultura, um certo estado do corpo, traduzindo a qualidade do trabalho cumprido pelos instintos e afetos. A elaboração da noção de saúde, que se substitui ao critério de verdade, representa a articulação capital da teoria da interpretação, pois, na falta de tal critério, a genealogia desapareceria no relativismo, e a tarefa do filósofo médico se reduziria a constatar os laços filológicos necessários entre corpo e componentes culturais.

Colocar a saúde como critério não implica simplesmente substituir uma norma por outra norma, mas comporta um deslocamento radical do questionamento filosófico: pois, contrariamente à verdade, ela não é pensada por Nietzsche como um conceito unívoco e normativo; ela escapa ao dualismo metafísico e encontra, para além disso, sua legitimidade numa certa relação com a experiência.

O idealismo é recusado num primeiro nível pelo fato de o critério elaborado pelo autor confirmar o primado do corpo como fonte de qualquer interpretação. Não há saúde "normal", e se a saúde não é a normalidade, é inicialmente porque ela é fundamentalmente múltipla. Como fica claro em uma passagem de A gaia ciência, "não há saúde em si [...] existem inumeráveis saúdes do corpo [...]. [Portanto,] nossos médicos deverão abandonar a noção de uma saúde normal" (Nietzsche, 1982b, p.146).

A saúde - ou para retomar o termo de Nietzsche, o "sucesso fisiológico" - se define de maneira completamente diferente daquela proveniente de uma ordem estatística. Muito longe de ser a norma, o sucesso constitui exceção: "encontramos na espécie humana, como em todas as outras espécies animais, um excedente de indivíduos fracassados, doentes, degenerados, enfermos, seres voltados ao sofrimento; também entre os homens os sucessos constituem sempre a exceção" (Nietzsche, 1971, p.77). 
Pode-se notar que a saúde não representa, em nenhum caso, uma versão nova da verdade ou do absoluto: o critério proposto por Nietzsche se conjuga com as linhas fundamentais de sua experiência de pensamento, confirmando a recusa do "em si". Ainda mais importante é o fato de que a recusa do idealismo é radicalizada pela rejeição de qualquer forma de dualismo metafísico: se a saúde não pode ser compreendida como uma norma, a doença também não pode ser pensada como anormalidade ou negação absoluta da saúde. Nesse caso, afirma Patrick Wotling (1995, p.122-3):

a consequência é a solidariedade fundamental entre saúde e doença, a hipótese da vontade de potência implicando na homogeneidade integral da realidade e, portanto, na rejeição de qualquer diferença de natureza entre esses dois termos. O trabalho do filósofo médico exige então uma profunda atenção às variações de grau, de dosagem relativa, que distinguem diferentes processos corporais.

Se as diferenças são apenas de grau, não encontraremos, em Nietzsche, qualquer nostalgia de uma saúde como pureza original, aspiração típica do niilismo e da fraqueza. A ideia de um organismo rigorosamente puro em relação a todo fenômeno patológico repousa apenas na crença em uma diferença de natureza entre saúde e doença, forma derivada do preconceito fundamental dos metafísicos, o dualismo.

Nietzsche justifica, enfim, o estatuto de critério que ele atribui à saúde por seu enraizamento na experiência, ponto sobre o qual esse novo critério, anti-idealista, se opõe à noção de verdade, que pretende mascarar sua origem corporal. A validade do experimento nietzschiano se atém, com efeito, à dupla experiência que ele reivindica, a da saúde, mas também a da doença: dupla natureza do corpo que está na origem da interpretação das interpretações que, como vimos, representa o texto de Nietzsche.

Toda a eficácia de sua teoria do valor dos valores se atém ao fato de que a saúde representa um critério estritamente interno. Se ele pode fazer com que a hostilidade à vida ou, ao contrário, o "sim" a ela, representem critérios de avaliação, sem menção explícita ao critério da saúde, é porque o conceito de saúde não tem outra significação a não ser traduzir o acordo entre uma interpretação particular e as exigências fundamentais da vida, e porque, por outro lado, a vida é pensada como vontade de potência. O exame clínico dos valores e das culturas que deles resultam, tal como realizado pelo filósofo médico, consiste, antes de tudo, em determinar o estado do corpo que os coloca como suas condições de existência, e em se interrogar sobre o acordo ou desacordo entre essas condições e as exigências da vontade de potência.

\footnotetext{
A saúde, enquanto acordo com as exigências da vontade de potência, não pode, portanto, designar outra coisa que não a aptidão do corpo para enfrentar a luta pelo domínio da realidade [...] longe de ser uma norma imposta do exterior sobre o corpo, a saúde traduz a capacidade que ele tem de interpretar eficazmente a realidade, ou seja, a capacidade que tem a vontade de potência de assimilar o real, chegando assim à intensificação do sentimento de potência. (Wotling, 1995, p.125-6)
}

Nestes termos, a saúde não é um estado neutro: ela designa, ao contrário, a capacidade do corpo de superar a doença.

Como vimos, saúde e doença não são valores contraditórios, mas processos solidários. Contrariamente à verdade, a saúde não é uma interpretação particular, mas o dinamismo próprio à vontade de potência. É por isso que Nietzsche prefere, ao termo doença, designações mais apropriadas para exprimir essa dinâmica, tais como os conceitos de decadência ou de declínio. Em suas Considerações intempestivas, ele afirma que "as doenças já são, em geral, sequelas da decadência e não suas causas" (Nietzsche, 1974c, p.77). Verdadeira perversão no funcionamento dos instintos, a decadência é o processo que tende a buscar aquilo que agrava as disfunções do corpo. Ao descrevê-la em termos de fisiologia, pela imagem da doença, Nietzsche define, paradoxalmente, os sintomas dessa doença por meio de determinações psicológicas, em particular pela presença de juízos negativistas. "Sob o nome de doença 
devemos entender: uma aproximação prematura da velhice, da torpeza e dos juízos pessimistas: todas essas coisas caminham juntas" (Nietzsche, 1980, p.224). De maneira simétrica, ele caracteriza a saúde e o estado do corpo conforme as exigências da vida por suas determinações psicológicas opostas: na perspectiva da psicologia da vontade de potência, a alegria, que seria preciso aproximar do sentimento de prazer, é a tradução da expansão do sentimento de potência e, portanto, da saúde.

Como não há saúde em si, o que existem são as inumeráveis saúdes dos diferentes corpos em suas singularidades. Para que isso tenha sentido, faz-se necessário abandonar o conceito de saúde normal e, mais do que isso, a ideia de regime ou curso normal da doença. Se a saúde não é o contrário da doença, dada a rejeição nietzschiana do dualismo, ela deve ser redefinida como processo dinâmico de ultrapassagem, e não entendida como um estado. Para Bilheran (2005, p.43), "a experiência da doença é indispensável e, de qualquer modo, inevitável. Qualquer projeto de erradicação da doença seria desprovido de sentido; tudo se atém ao comportamento face à doença, ao tratamento que um determinado tipo de sistema pulsional em seu conjunto dará a ela".

Para além dessa relação de composição com a doença, é impossível normatizar a saúde, inscrevendo-a em uma definição essencialista; só existem saúdes individuais (e plurais, no próprio seio da evolução de cada um), elaboradas no terreno de doenças individuais, das quais só se avalia a gravidade com relação aos afetos sadios ou mórbidos (que louvam a vida ou, ao contrário, depreciamna). A verdadeira saúde se define e se honra enquanto tal em seu combate com a doença, um combate de conquistas e sacrifícios. "A grande saúde - uma saúde que não nos contentamos em ter, mas que ainda conquistamos e devemos conquistar continuamente, porque a sacrificamos e devemos sacrificá-la incessantemente!" (Nietzsche, 1982b, p.292, grifado no original).

A saúde não consiste, em última instância, no combate interior contra um elemento mórbido, eliminando uma parte vital de si que residiria no adversário interno, mas em fundar uma coexistência pacífica entre afetos, em uma esfera transfigurada. A saúde é dionisíaca: não se trata de matar as zonas de sombra, mas de incluí-las em um movimento de alegria que as supera, assim como Dionísio é o paradigma de um trágico superado na alegria, mas não eliminado. Essa grande saúde engloba todos os niilismos para transfigurá-los.

A saúde que se desvela no afrontamento com, e depois na vitória sobre a doença, é aquilo que Nietzsche chama de "grande saúde", ou melhor, a verdadeira saúde. Reforçar a si próprio é a essência da saúde; se destruir é a essência da doença. Essa saúde se define pelo movimento; como a vida, ela é sempre movimento.

A grande saúde é um paradigma do pensamento nietzschiano, no que a sua estrutura permite pensar a da vontade de potência. Esta vontade

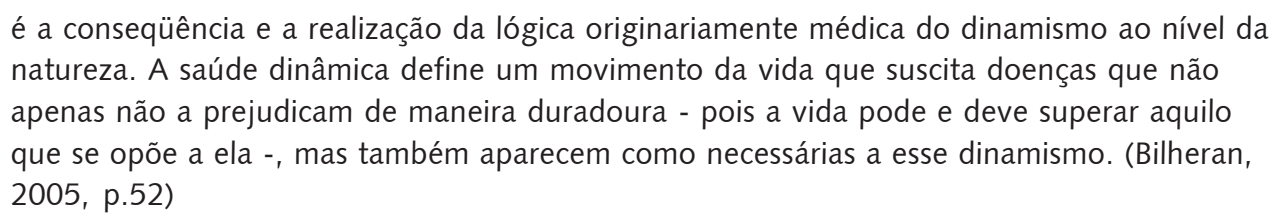

A vida não é apenas vontade de viver e se conservar: viver significa querer a potência. A vontade de potência é exigência de sempre se superar, como a saúde é exigência de se colocar em causa, expondo-se à doença, a fim de se fortificar através de uma contínua vitória sobre ela. Do mesmo modo, o declínio é, para a vontade de potência, o que a doença temporária (a doença como meio) é para a saúde dinâmica.

Se a saúde se define essencialmente pela faculdade de superar a doença e, em particular, a doença grave no caso da "grande saúde", estar bem de saúde consiste em acolher a doença - e não rejeitá-la ou negá-la - para melhor afrontá-la em seguida. Como a vida não escapa ao patológico, não existe outra saúde que não a temporária e conquistada sobre a doença. A saúde se define, em suma, pela cura da doença, a saber, uma saúde que inclui em si a doença, superando-a. Ela é um dinamismo mais que um estado, um movimento de autointensificação, contrariamente à concepção médica comum segundo a qual ou estamos saudáveis ou estamos doentes. 
Além disso, as noções de saúde e doença, tal como ocorre com o corpo, não são estritamente assimiladas a fatos orgânicos, mas designam acontecimentos notáveis para aquele que quiser saber um pouco mais sobre o estado de seu próprio pensamento e, geralmente, sobre a gênese de qualquer pensamento.

A grande saúde envolve forças concentradas ao extremo, e contraditórias em último grau. Elas são contidas por uma firme vontade de impor lei e conhecimento. O sintoma dessa grande saúde é a capacidade de se servir da doença. A aptidão para fazer dela uma admirável arma para o conhecimento. Trata-se de saber curar acima de todos os males que se inflija, como o indica o prefácio de 1886 de Humano Demasiado Humano: "esta saúde transbordante que se regozija de recorrer à própria doença, meio e armadilha do conhecimento [...] esta superabundância que é justamente o índice da grande saúde e que ao espírito livre dá o privilégio arriscado de viver à prova e de se oferecer à aventura" (Nietzsche, 1968, p.11).

A grande saúde, portanto, não é nada além de ter suficiente abundância em si para se permitir cair doente a fim de reunir em si todos os tipos de conhecimentos. A busca genealógica calcula os valores através da doença. Mas, seria ela possível se, no fundo, aquele que busca não percebesse nele uma força soberana o suficiente para tudo suportar, tolerar, em nome de sua paixão por conhecer? De acordo com Montebello (2001, p.109-10),

é sob a legislação dessa força que [a] paixão de conhecer se transforma em paixão do corpo, que o corpo se torna o terreno de experimentação para o conhecimento: sob a tutela de tal força, o filósofo médico não hesita em oferecer o corpo que sofre por amor ao conhecimento, ele quer até crucificá-lo pelo futuro do homem, sempre como indício de superabundância de sua vontade, na certeza de sua cura.

Nota-se que aqui, para além de sua pura dimensão metafórica destacada por Blondel, e que discutimos acima, o corpo torna-se uma espécie de plano de imanência, um espaço de experimentação para as forças, a partir do qual é possível delimitar estados saudáveis ou doentios.

A grande saúde também é a capacidade de viver o conjunto dos valores. Ela não é a saúde daquele que nunca fica doente, mas a daquele que teve todas as doenças, ou melhor, que aspira ter todas as doenças. A possibilidade de retraçar em si a gênese de todos os tipos de pensamento a partir da experiência corporal, na medida em que as formas de pensamento são a expressão do combate das forças no corpo, requer essa grande saúde. "Aquele cuja alma aspira viver toda a amplitude dos valores e das aspirações que prevaleceram até agora", diz Nietzsche em A gaia ciência, "este tem a necessidade em primeiríssimo lugar de uma coisa: a grande saúde" (Nietzsche, 1982b, p.291-2).

\section{Considerações finais}

Conforme podemos deduzir das reflexões sobre corpo e saúde analisadas neste artigo, Nietzsche propõe uma atitude trágico-dionisíaca diante do sofrimento, opondo-a à reação decadente-niilista que prega uma dicotomia radical prazer-sofrimento, formulando uma concepção idealista de felicidade como ausência de qualquer sofrimento. Se o estatuto desse sofrimento deve ser repensado em conformidade com a atividade da vontade de potência, ele não pode ser visto como uma anomalia suscetível de ser eliminada, dado que é parte de nossa existência. Rejeitá-lo totalmente seria rejeitar a própria vida da qual ele é uma dimensão essencial. Ainda que considere a dor como um elemento fundamental da vida, Nietzsche se recusa a fazer dela o signo de uma lesão corporal. Neste sentido, a ausência ou presença de dor não podem, de modo algum, ser consideradas sinônimo de saúde. Mas o sofrimento também não pode ser tomado como essência última da vida ou princípio de realidade, pois isso seria condenar a própria vida como instância determinante da existência. Ele é apenas mais um índice de variação do sentimento de potência, do seu crescimento ou declínio. A força não deve condenar nem ser insensível ao sofrimento em seu caráter problemático, mas deve poder enfrentá-lo. A cultura como 
negação da vida implica justamente a incapacidade de enfrentar o sofrimento como expressão particular da vontade de potência.

O niilismo do fraco é um estado declinante da vontade de potência que não suporta praticamente nenhum desprazer. Buscando assimilar a realidade na sua totalidade trágica, o criador dionisíaco procura dominar o sofrimento e fazer dele um estimulante da vontade de criar ou uma condição de ultrapassagem de si mesmo. Neste sentido, dizer sim à vida é recusar a decadência, o ressentimento e a má consciência - os quais transformam o sofrimento em objeção ou motivo único para o viver aceitando os estímulos provenientes das forças antagônicas. O sim à vida não é, de modo algum, uma aceitação resignada da dor, mas uma luta contra ela. E é essa luta que representa a forma suprema da afirmação. Afirmação que devemos contrapor, nos dias de hoje, ao culto ao corpo como pretensão puramente narcísica, e à saúde normativa como assepsia com pretensões de hegemonia absoluta. Pois esse corpo e essa saúde - que nada têm a ver com as propostas nietzschianas - são, em última instância, apenas novas modalidades de recusa da singularidade que é própria à vida.

\section{Referências}

BILHERAN, A. La maladie, critère des valeurs chez Nietzsche: premices d'une psychanalyse des affects. Paris: L'Harmattan, 2005.

BLONDEL, E. Nietzsche le corps et la culture. Paris: PUF, 1986.

DELEUZE, G. Nietzsche e a filosofia. Rio de Janeiro: Editora Rio, 1976.

GIACOIA JUNIOR, O. Corpo: ponte para o mundo. In: FONSECA, T.M.G.; KIRST, P.G. (Orgs.). Cartografias e devires: a construção do presente. Porto Alegre: Editora da UFRGS, 2003. p.23-42.

Nietzsche como psicólogo. São Leopoldo: Editora Unisinos, 2001.

KLOSSOWSKY, P. Nietzsche e o círculo vicioso. Rio de Janeiro: Pazulin, 2000.

MONTEBELLO, P. Vie et maladie chez Nietzsche. Paris: Ellipses, 2001.

NIETZSCHE, F. La généalogie de la morale. Paris: Le Livre de Poche, 2000. 1982a.

Fragments posthumes (automne 1884 - automne 1885). Paris: Gallimard,

Le gai savoir. Paris: Gallimard, 1982b.

Aurore. Paris: Gallimard, 1980.

$\overline{1979 .}$

Fragments posthumes (automne 1885 - automne 1887). Paris: Gallimard,

Fragments posthumes (automne 1887 - mars 1888). Paris: Gallimard, 1976.

L'Antéchrist. Paris: Gallimard,1974a.

Ecce homo. Paris: Gallimard, 1974b. 
NIETZSCHE, F. Crépuscule des idoles. Paris: Gallimard 1974c.

Par-delà bien et mal. Paris: Gallimard, 1971.

Ainsi parlait Zarathoustra. Paris: Aubier-Flammarion, 1969.

Humain, trop humain. Paris: Gallimard, 1968.

WOTLING, P. Nietzsche et le problème de la civilisation. Paris: PUF, 1995.

PEIXOTO JUNIOR, C.A. Algunas consideraciones nietzscheanas sobre cuerpo y salud. Interface - Comunic., Saude, Educ., v.14, n.35, p.727-38, out./dez. 2010.

Con el intuito de resaltar la importancia de algunas consideraciones nietzscheanas para el entendimiento que se puede tener del cuerpo y de la salud, el presente trabajo parte de la crítica formulada por Nietzsche a la metafísica y al platonismo para discutir su punto de vista a propósito de las relaciones entre cuerpo y conciencia. A partir de lo cual, y teniendo como principal referencia el concepto de voluntad de potencia, se trata de mostrar como el cuerpo podría concebirse como una metáfora a la que recorre Nietzsche en su interpretación crítica de la subjetividad y de la cultura.

Palabras clave: Cuerpo. Salud. Conciencia. Interpretación.

Recebido em 05/12/09. Aprovado em 12/04/10. 